\title{
O DESENVOLVIMENTO DA APRENDIZAGEM Á LUZ DA TEORIA COGNITIVA
}

\author{
THE DEVELOPMENT OF LEARNING IN THE LIGHT OF COGNITIVE THEORY \\ EL DESARROLLO DEL APRENDIZAJE A LA LUZ DE LA TEORÍA COGNITIVA
}

\author{
Flávia Nobre Pereira \\ Juliane Amorim \\ Sirley Leite Freitas
}

\begin{abstract}
RESUMO
O presente artigo surge como resultado de uma pesquisa que tem como foco analisar teorias da psicologia da aprendizagem apontando suas contribuições para a educação e seu auxílio no processo de construção do conhecimento do educando. Para tanto decidimos abordar o desenvolvimento da aprendizagem, baseado na teoria cognitiva. Assim este estudo tem por objetivo evidenciar conceitos e ideologias do desenvolvimento cognitivo dos indivíduos segundo o pensamento de Jean Piaget. Sua teoria do desenvolvimento cognitiva é uma teoria de etapas, que os seres humanos passam por uma série de mudanças ordenadas perceptíveis. Precisamos nos adaptar ao meio físico e as organizações do ambiente, sempre buscando um equilíbrio. A relação num desenvolvimento sintético mutua e progressivo e acompanhado de 04 processos: esquema, assimilação, acomodação e equilíbrio. Estes que necessitam do tempo para desenvolverem de forma plena sem prejuízo, pois se torna uma sequência que necessita dos processos anteriores para o sucesso no período.
\end{abstract}

PALAVRAS-CHAVE: Cognitivismo. Desenvolvimento. Ensino.

\section{ABSTRACT}

This article arises as a result of research that focuses on analyzing theories of learning psychology, pointing out its contributions to education and its aid in the process of building the student's knowledge. To this end we decided to approach the development of learning, based on cognitive theory. Thus this study aims to highlight concepts and ideologies of cognitive development of individuals according to the thinking of Jean Piaget. His theory of cognitive development is a theory of steps, in which humans undergo a series of noticeable ordered changes. We need to adapt to the physical environment and environmental organizations, always seeking a balance. The relationship in a mutual and progressive synthetic development and accompanied by 04 processes: scheme, assimilation, accommodation and balance. These need the time to fully develop without prejudice as it becomes a sequence that needs the previous processes for success in the period.

KEYWORDS: Cognitivism. Development. Teaching.

\section{RESUMEN}

Este artículo surge como resultado de una investigación que se centra en analizar las teorías del aprendizaje de la psicología, señalando sus contribuciones a la educación y su ayuda en el proceso de construcción del conocimiento del estudiante. Con este fin, decidimos abordar el desarrollo del aprendizaje, basado en la teoría cognitiva. Así, este estudio tiene como objetivo resaltar conceptos e ideologías del desarrollo cognitivo de los individuos según el pensamiento de Jean Piaget. Su teoría del desarrollo cognitivo es una teoría de pasos, en la cual los humanos sufren una serie de cambios ordenados notables. Necesitamos adaptarnos al entorno físico y a las organizaciones medioambientales, siempre buscando un equilibrio. La relación en un desarrollo sintético mutuo y progresivo y acompañada de 04 procesos: esquema, asimilación, acomodación y equilibrio. Estos necesitan el tiempo para desarrollarse completamente sin prejuicios, ya que se convierte en una secuencia que necesita los procesos previos para tener éxito en el período.

PALABRAS CLAVE: Cognitivismo Desarrollo. Docencia

Revista de Ciências Humanas, Frederico Westphalen - RS, v. 21, n.2, p. 3-10, maio/ago. 2020.

\begin{tabular}{l|l} 
Recebido em: 10/04/2020 & Aceito em: 25/04/2020
\end{tabular}




\section{INTRODUÇÃO}

O desenvolvimento da aprendizagem é norteado por diversas teorias, entre elas a Cognitiva, na qual tem o intuito de explicar o processo de conhecimento humano, que teve como principal defensor Jean Piaget, este que foi um cientista suiço de grande influencia no âmbito da educação, mas nunca atuou como pedagogo. "De fato, há muitos anos, inúmeros educadores e pedagogos de diversos países se referem explicitamente à obra de Piaget para justificar suas práticas ou princípios" (ROCHA, 2010).

A permanência desta teoria em sala de aula se dá pelo fato de verificar que se torna imprescindivel a compreensão de cada fase do desenvolvimento, assim ocorre a necessidade de conhecimento e de buscar informações sobre a teoria cognitiva.

Tendo em vista que a cognição se refere à forma de percepção, ou seja, o raciocínio. É extremamente importante entendê-la, para utilizar técnicas mais apropriadas de educação em cada caso. Assim, este estudo tem por objetivo evidenciar conceitos e ideologias do desenvolvimento cognitivo dos indivíduos segundo o pensamento de Jean Piaget.

Refletindo sobre como a teoria piagetiana pode ser utilizada em sala de aula e como as fases do desenvolvimento cognitivo interferem no aprendizado e desenvolvimento das crianças.

Para uma melhor compreensão este estudo foi estruturado em duas partes. Primeiro, 0 desenvolvimento escolar baseado em como os estágios do desenvolvimento cognitivo (sensóriomotor, pré-operatório, operatório concreto e operações formais), está ligado à educação e que em cada fase é fundamental saber como interagir com a criança, uma vez que há características bem marcantes. E a segunda qual a influência da teoria piagetiana em sala de aula, diante as mudanças que são necessárias para uma educação melhor.

\section{METODOLOGIA}

A partir de discussões ocorridas nas aulas da disciplina de Psicologia da Educação no terceiro período, do curso de Licenciatura em Matemática, no ano de 2018, no Instituto Federal de Educação, Ciência e Tecnologia de Rondônia - IFRO/Campus Cacoal, surgiu a necessidade de pesquisar as teorias da psicologia da aprendizagem e suas contribuições para o processo de ensino e aprendizagem. Para tanto, foi elaborado um projeto de pesquisa a fim de expandir 0 conhecimento referente as teorias, subdividindo a turma para que fosse possível atingir o maior número possivel de teorias.

0 texto foi elaborado por meio da sintetização das ideias, abordando as informações coletadas, como também dados levantados por meio de pesquisas em sítios virtuais e livros, artigos científicos referentes à Teoria Cognitiva. Foi identificado e selecionado o material bibliográfico pertinente para, em seguida proceder à leitura e fichamento em formato digital do material selecionado com identificação de obras, dos autores e suas ideias centrais. 0 terceiro passo foi à elaboração de uma lista de palavras-chave referentes a assuntos relevantes para a 
pesquisa que facilite a localização dos temas no material fichado no momento de construção do relatório final. E, por último, a análise dos dados coletados e escrita das discussões e resultados.

\title{
DESENVOLVIMENTO ESCOLAR
}

Ao estudar psicologia Jean Piaget percebeu que crianças na mesma faixa etária cometiam erros e equívocos muitos parecidos, de modo que se deparou com um questionamento que 0 despertou interesse: Como ocorre o desenvolvimento da criança? "Um dos grandes temas da epistemologia é saber como se passa dá um estado de menor conhecimento para um estado de maior conhecimento, de um conhecimento de menor valor para um conhecimento de maior valor" (CUNHA, 2015, p. 66). Ao analisar as fases de desenvolvimento Piaget chegou à conclusão de que:

\begin{abstract}
A principal característica do primeiro período de desenvolvimento, chamado sensóriomotor, é a inexistência de representações, imagens mentais dos objetos que cercam o indivíduo. O conhecimento, nesse caso, é constituído por impressões que chegam ao organismo por meio dos órgãos dos sentidos e do aparelho motor. Podemos dizer, então, que a criança age sobre aquilo que alcança com as mãos, aquilo que ouve e vê, aquilo que chega a sua boca, sem, contudo, formar imagens mentais desses objetos. (CUNHA, 2015, p.66).
\end{abstract}

Nesta fase o conhecimento é adquirido por meio do tato e visão onde ocorre a necessidade de a criança sentir ou ver o objeto para que seja real, a partir do momento que este objeto desaparece do seu alcance ele deixou de existir. Essas características se aprimoram na segunda fase em que a criança mesmo que não tenho mais o objeto sobre seu alcance tem o conhecimento que ele existe e buscar por ele. Além disso, outro fator de transição entre a primeira e segunda fase é a imitação, fundamental para a criança se desenvolver e utilizar em outras situações por meio de assimilação. Assim tem como característica mais marcante do segundo período de desenvolvimento é a representação, a transformação de esquemas -e esquemas combinados- de ações em esquemas representativos (Cunha, 2015). Desta forma a mente começa a desenvolver estratégias formas de resolver o problema, tendo base em situações que já ocorreram.

Assim como descreve Piaget (1967) apud Chaves ( [s/d],p 203):

[...] a criança adota simplesmente adota simplesmente uma atitude idêntica diante dos objetos que se prestam a uma assimilação, sem ter necessidade de tomar consciência desta identidade de atitude. Ela "age", pois, por assim dizer, à semelhança, sem ainda "pensa-la". Contrariamente, a diferença dos objetos cria uma desadaptação, e é esta desadaptação que ocasiona a tomada de consciência[...].

É nítido que o processo de assimilação adquirido na primeira fase se transforma em representação na segunda fase, ou seja, demonstra a evolução da aprendizagem, lembrando que essa divisão de fases não é genérica e pode variar conforme característica tanto biológica quanto sociais, por isso é considerado apenas como referência. Ao observar o desenvolvimento nessas duas fases percebe- se que a criança vai retendo o conhecimento e assimilando em qualquer situação, assim gerando possibilidades e desenvolvendo a capacidade. A partir da segunda fase 
esse conhecimento começa a ficar mais concreto, a criança começa a perceber o que deve fazer em cada situação. Os mecanismos que compões o processo de adaptação são a assimilação, que é o utilizar-se de incorporações já feitas anteriormente em situações novas, e a acomodação, que é o criar novos comportamentos diante de situações que requerem novos esquemas (BAETA, 2006).

$\mathrm{Na}$ terceira fase a criança começa a aprimorar a lógica, conseguindo criar imagens e caminhos, além disso, nessa etapa se estabelece o inicio da compreensão tanto do tempo quanto do espaço, podendo então relacionar a realidade com mais facilidade. Assim como o processo inverso de representações antes vistas, por isso que nessa fase a educação tem fundamental importância, já que é o período em que a criança começa o processo de desenvolvimento intelectual, como descreve Piaget (1950) apud Cunha (2015, p 71):

\begin{abstract}
Nesse novo período, que vai dos 7 aos 12 anos, aproximadamente, o pensamento da criança ganha a maleabilidade que não possuía até então, sendo capaz de operar mentalmente com esquemas de ação que até o momento eram apenas representados. Com base nas aquisições sensoriais e motoras do primeiro período, a criança consegue percorrer um trajeto dentro de sua casa. Mais tarde, descreve o trajeto percorrido, dada a capacidade de formar a imagem mental de suas ações, capacidade está adquirida no segundo período. Agora, já consegue elaborar mentalmente o trajeto inverso, do ponto final ao ponto de início.
\end{abstract}

Nesse período de descobrimentos é necessária à instigação ao conhecimento, por ser 0 período em que a criança começar a frequentar a escola os professores tem o dever de procurar meios, formas de buscar o desenvolvimento da capacidade de cada indivíduo. Nessa fase em que a criança começa a ter um conhecimento é importante que os professores utilizem diversas metodologias, pois será nessa fase que a criança pode tomar aversão a determinado conteúdo, geralmente ocorre com a matemática. Pois no momento que a criança não consegue desenvolver o conhecimento por não ter o conhecimento abstrato de tal forma de realizar as operações matemáticas é necessária uma intervenção do profissional da educação.

A compreensão matemática não é questão de aptidão da criança. É um erro supor que um fracasso em matemática obedeça a uma falta de aptidão. A operação matemática deriva da ação: resulta que a apresentação intuitiva não basta, a criança deve realizar por si mesma a operação manual antes de preparar a operação mental. (...) Em todos os domínios da matemática, o qualitativo deve preceder ao numérico" (PIAGET, 1950, p.79 e 80 apud MUNARI, 2010, p.19).

Como Piaget descreve tem que ocorrer a contextualização, estimular a criança avaliar sobre outras perspectivas. Isso ocorre também com a leitura, por essa razão é necessário que ela obtenha um conhecimento para que consiga realizar uma interpretação do que está lendo, consiga assimilar a leitura com o conhecimento que já adquiriu como significado de palavras, ou seja, não basta ler no sentido apenas pronunciar varias palavras, mas sim entender 0 que aquelas palas juntas transmitem, ou seja, interpretar a mensagem.

Não é difícil perceber que o indivíduo humano transita, ao longo de sua vida, de um estado de menor conhecimento para um estado de maior conhecimento. Pode-se levar uma criança pequena a concluir que $5+2=7$ e que o trajeto mais curto entre dois pontos é uma linha reta, mais para isso será preciso, num caso, permitir-lhe manipular objetos 
- palitinhos de fósforo ou grãozinho de milho - e, no outro, andar de uma cadeira a outra experimentando vários trajetos, por exemplo. Ano mais tarde, esse mesmo indivíduo trabalhará mentalmente com esses enunciados, da matemática e da geometria, como se fossem realidades indiscutíveis, sem necessitar dos palitinhos e das cadeiras (CUNHA, 2015, p.58).

Este período, ainda é marcado por manipulações principalmente de objetos concretos.

Este estado menor de conhecimento passa para um estado maior de conhecimento, conforme experiências e problemas que exigem raciocínio para resolver. Esta fase que vai até os 12 anos a criança terá o domínio de relacionar caminhos ou soluções independentes da situação. Ela terá a maturidade de resolver tal problema e situação de forma inversa sem nenhuma dificuldade. Após ter adquirido certo grau de abstração e de ser capaz de coordenar ações cada vez mais gerais, o sujeito passa a podre dispensar os objetos concretos e operar em nível simbólico e de maneira dedutiva (BAETA, 2006).

Desta forma, esse período é de fundamental importância, pois assim que adquire a capacidade de raciocínio com ou sem manuseio de objetos sua capacidade intelectual será beneficiada assim proporcionado à aptidão para que se inicie a próxima fase assim obtendo êxito no seu pleno desenvolvimento.

No último período a capacidade de adaptação se abrange, o individuo consegue formular hipóteses e compreender ás constantes mudanças em sua volta, criando a própria maneira de ver o mundo, chegando ao ápice do desenvolvimento, pois não se limita a representações. Conseguindo manipular representações abstratas.

Entre os 12 e 16 anos de idade, aproximadamente, o indivíduo vivência 0 desenvolvimento do quarto período, chamado operatório-formal. Sua principal característica é a transformação dos esquemas cognitivos até então organizados, capazes de realizar operações concretas, em esquemas que operam com base em realidades apenas imaginadas como possíveis (CUNHA, 2015, p.73).

Nessa fase a criança consegue entender experiências vividas por outras pessoas. Assim como compreender opiniões em relação a objetos abstratos.

[...] Quando a reflexão compreende que sua função não é contradizer, mas se adiantar e interpretar experiências. Este equilíbrio, então, ultrapassa amplamente a do pensamento concreto, pois, além do mundo real, engloba as construções indefinidas da dedução racional e vida do interior (PIAGET, 1976, p.65 apud GOULART, 2018, p. 08).

Aqui o período é marcado pelo início da maturidade, o senso crítico de realidade costuma ser uma fase de intensas conturbações, pois os adolescentes buscam saber o motivo de todas as $s$ descobertas, o que fez chegar a tal solução, assim marcando como uma fase de intensas descobertas. Nesse período faz se necessário uma orientação, pois acabam sendo expostas as diversas situações nessa busca do saber.

Nessa etapa o jovem compreende melhor abstrato, conseguindo entender a probabilidade de algo, já que tem expansão do seu pensamento com a dedução e formulação de hipóteses sobre determinadas situações. Para que possa distinguir o que é possível se fazer. 


\section{A TEORIA PIAGETIANA EM SALA DE AULA}

Para Piaget é preciso que ocorra mudanças na educação, por isso entender como é o desenvolvimento do conhecimento é primordial para detectar onde precisa melhorar. Portanto os profissionais da educação devem trabalhar o desenvolvimento espontâneo, mas isso não significa deixar a criança fazer o que quiser e sim propor atividade em que um problema se resulta em outro, e que possa posteriormente ser utilizado em outras situações. Dar liberdade para que a criança instigue sua curiosidade e deixe-a questionar, para que assim consiga se expressar claramente. De modo que não apenas acumule varias informações, mas sim possa dar sentido à junção dessas informações adquirindo conhecimento.

Do mesmo modo, pode-se falar que a experiência perceptiva dos sentidos não consiste em puro registro ou na simples "leitura" da experiência, à medida que levam a uma organização do espaço pelo estabelecimento de relações ativas e progressivas, relações estas que podem ser simples transportes visuais de um elemento para outro ou relações complexas de transposições, que são a origem das proporções, das relações de tamanho e também de referências individuais (SENICIATO; CAVASSAN, 2008, p.07)

Para que a criança consiga absorver o conhecimento, ela mesma precisa realizar as atividades propostas, já que somente observar o educador não é suficiente. Essa é a razão pela qual o educador tem que escolher maneiras para que todas as crianças presentes naquele momento consigam se envolver diretamente ou indiretamente com a atividade, resultado em um maior proveito (SENICIATO; CAVASSAN, 2008). Isso enriquece o trabalho do educador, por haver a possibilidade de desenvolver de formas diferentes, ou seja, um consegue aprender com o outro através do compartilhamento de ideias. Além disso, ter a liberdade de inovar, para que as crianças usem sua imaginação para criar situações, e não só repetir algo existente.

Para Piaget, o principal objetivo da educação é criar indivíduos que sejam capazes de fazer coisas novas e não simplesmente repetir aquilo que outras gerações fizeram. Isto significa dizer que a educação não pode mais trabalhar para que os alunos apenas memorizem, mas principalmente para que estes alunos além de memorizar sejam autônomos para inventar, produzir e criar novos conhecimentos, que esses alunos não conheçam somente o produto do ensino, mas participem do processo de construção do produto (GOMES; GHEDIN, [s/d], p.07).

Os processos cognitivos estão presentes em cada momento tanto ao prestar atenção, quanto ao se adaptar a determinadas situações, instigando uma atitude inteligente, para resolver possíveis problemas de forma satisfatória.

Diante disso Piaget sempre considerou que o conhecimento está sempre em constante aprimoramento, tendo em vista que não chega ao fim, sempre há algo a mais para se aprender dessa maneira o processo de aprendizado tem diferentes formas, mas é de fundamental importância que o educador consiga que haja interação de seus alunos para que eles não apenas

Revista de Ciências Humanas, Frederico Westphalen - RS, v. 21, n.2, p. 3-10, maiolago. 2020. 
recebem a informação, mas sim desenvolva e inove em futuras situações, assim como consiga trabalhar com atividades que abrange o estágio de desenvolvimento no qual o aluno está.

\begin{abstract}
Por meio da teoria piagetiana, o professor pode saber quando ensinar determinado conteúdo e de que forma deve ser ensinado, pois pelos estágios estudados por Piaget, é possível visualizar o desenvolvimento dos sujeitos e o que the é possível aprender em determinado estágio. Isto significa dizer, que o professor sabe quando e como ensinar ao seu estudante e que desenvolvimento pode-se esperar dele, dependendo do estágio pelo qual está passando. Em suma, é importante respeitar o desenvolvimento do estudante e a forma como este aprende (GOMES; GHEDIN, [s/d], p.08).
\end{abstract}

É notório compreender como a teoria piagetiana teve grande contribuição na educação, tendo em vista que com o conhecimento do desenvolvimento da criança, facilita a compreensão de como ela aprende, assim o professor consegue procurar maneira de se adequar a cada fase para que consiga o maior êxito em seu trabalho, uma vez que cada informação apresentada aos seus alunos será organizada conforme a estrutura cognitiva de cada indivíduo (GOMES; GHEDIN, $[\mathrm{s} / \mathrm{d}])$.

Desta forma, a aplicação da Teoria de Piaget em sala de aula fará com que o individuo busque a resposta, a solução tendo como suporte somente a orientação do profissional da educação assim possibilitando novas descobertas e construção do conhecimento para que seja possível expandir a compreensão.

\title{
CONSIDERAÇÕES FINAIS
}

Pode-se perceber que a compreensão de como funciona cada período e 0 desenvolvimento até 0 final da adolescência é suma importância tendo em vista que ao compreender, temos o domínio de lidar e assim verificar o que é possível ocorrer em cada fase e como deve ocorrer assim evitando retardo e sem exigir características inapropriadas para cada fase. No âmbito escolar essas fases desenvolvimento interferem diretamente, pois no momento que os profissionais da educação que atuam em sala de aula vão utilizar métodos é importante que se veja o mais apropriado. De forma geral, Jean Piaget aprimorou uma teoria que está presente até a atualidade em sala de aula.

Sendo assim os profissionais da educação e muitos psicólogos estudam sua teoria em relação à educação das crianças e seu desenvolvimento, que são por etapas. Cada etapa tem um significado e sua importância de modo que as crianças não agem como os adultos como mostra as pesquisas de Piaget que foram de extrema importância para a sociedade.

\section{REFERÊNCIAS}

BAETA, A. M. Psicologia e Educação. Rio de Janeiro: Forma \& Ação, 2006. 
CHAVES,V.R. Jean Piaget: o raciocínio na criança.

CUNHA, M. V. Psicologia da Educação. Rio de Janeiro: Lamparina, 2008.

SENICIATO, T.; CAVASSAN, O. Afetividade, motivação e construção de conhecimento científico nas aulas desenvolvidas em ambientes naturais. Bauru: Ciências \& Cognição, 2008.

MUNARI, A. Jean Piaget. Recife: Fundação Joaquim Nambuco. Editora Massangana, 2010.

GOMES, R.C. S; GHEDIN, E. O Desenvolvimento Cognitivo na Visão de Jean Piaget e Suas Implicações a Educação Científica. Universidade do Estado do Amazonas\& Universidade do Estado de Roraima, [s/d].

GOULART, F.O. Desenvolvimento Global Segundo Piaget: período operatório formal. Universidade Luterana do Brasil: Canoas, 2018. 